\title{
Risk Assessment in Surgical Patients: American Society of Anesthesiologist's (ASA) Classification vs Intraoperative Therapeutic and Diagnostic Interventions (I-ITS)
}

\author{
Banu Cevik*, Yucel Yuce \\ University of Health Sciences Kartal Dr. Lutfi Kirdar Education and Research Hospital, \\ Department of Anesthesiology and Reanimation, Istanbul, Turkey \\ *Corresponding author: banueler@yahoo.com
}

\begin{abstract}
Background: In this prospective study of 859 surgical patients in a tertiary research hospital, we examined the association between ASA physical status classification and Intraoperative Therapeutic Intervention Score (I-TIS). Methodology: All patients were assigned by ASA classification before the operation and received a value of 1-4 points for I-TIS score during surgical procedures. Surgical complexity was also classified and correlation with I-TIS was examined. Results: The correlation coefficient of the ASA with I-TIS was $\mathrm{r}=0.55$ $(\mathrm{p}<0.01)$. The correlation between the surgical complexity was $\mathrm{r}=0.66(\mathrm{p}<0.001)$. Five patients (ASA IV) with I-TIS score $>25$ and surgical complexity of major plus were admitted to the intensive care unit. Two of them were followed up six hours and the other three stayed more than 24 hours in the intensive care unit. Conclusions: It's concluded that I-TIS score may be validated for our surgical patients but this assessment may show variability among institutions. The ASA classification is the most valued and widely used scoring system for evaluation of perioperative risk in surgical patients. It is simple, easy and also a useful tool to assist descriptions of workload and 'anesthetic risk' for analysis and research purposes.
\end{abstract}

Keywords: operative, surgery, anesthesia, scoring system

Cite This Article: Banu Cevik, and Yucel Yuce, "Risk Assessment in Surgical Patients: American Society of Anesthesiologist's (ASA) Classification vs Intraoperative Therapeutic and Diagnostic Interventions (I-ITS)." American Journal of Clinical Medicine Research, vol. 6, no. 1 (2018): 15-19. doi: 10.12691/ajcmr-6-1-4.

\section{Introduction}

It's inevitable that perioperative morbidity and mortality are influenced by the patient's health status, the complexity of the surgical procedures and success of the anesthetic management. Risk predictors and scoring systems are commonly used in surgical patients to provide a reliable and objective estimation of disease prognoses, the probability of adverse events and outcome. American Society of Anesthesiologist's (ASA) classification has established itself as the most widely used patient risk assessment scheme in anesthesia despite being developed in 1942 by Saklad [1] for the purpose of statistical data management. The classification was revised in 1963 with the number of classes being reduced from seven to five and the emergency operation was noted by placing an "E". ASA physical status classification and Goldman cardiac risk score [2] are the widely used methods to evaluate operative risk. There are many risk assessment scores for surgical patients but most of these are presented for the evaluation of complexity of surgery [3]. However, Klein [4] designed a study for the intraoperative evaluation of patients and outcome after surgery. This Intraoperative
Therapeutic Intervention Score (I-TIS) was developed by using a scoring scheme similar to that used by the therapeutic intervention score system (TISS) introduced by Keene and Cullen [5]. We adapted the I-TIS scoring system to our surgical patients and examined its validity by comparing it with ASA.

\section{Material and Methods}

In this prospective study, all surgical patients without age limit were included in the study group for a limited time period. Cardiac surgery, Cesarean delivery and emergency operations were excluded. All patients were assessed before operation by an anesthetist and assigned by ASA classification (Table 1). Specific data retrieved from a pre-prepared form checked by the responsible anesthesiologist for each patient. This form included ASA physical status classification, age, operative procedures, duration of anesthesia and I-TIS score (Table 2). The outcome of the patients after surgery was evaluated as short postoperative stays (less than 1 hour) in the recovery room, follow-up between 1-3 hours in the recovery room and intensive care follow-up $<24$ or $>24$ hours. Operations were classified according to 
Copeland et al [3] and modified according to our surgical patient profile (Table 3).

Table 1. American Society of Anesthesiologists' (ASA) physical status classification

\begin{tabular}{ll}
\hline Class & Description \\
\hline I & Healthy patient \\
II & Mild systemic disease-no functional limitation \\
III & Severe systemic disease-definite functional limitation \\
IV & Severe systemic disease that is a constant threat to life \\
V & Moribund patient unlikely to survive $24 \mathrm{~h}$ with or without operation \\
\hline
\end{tabular}

Table 2. Intraoperative Therapeutic Intensity Score (I-TIS) [4]

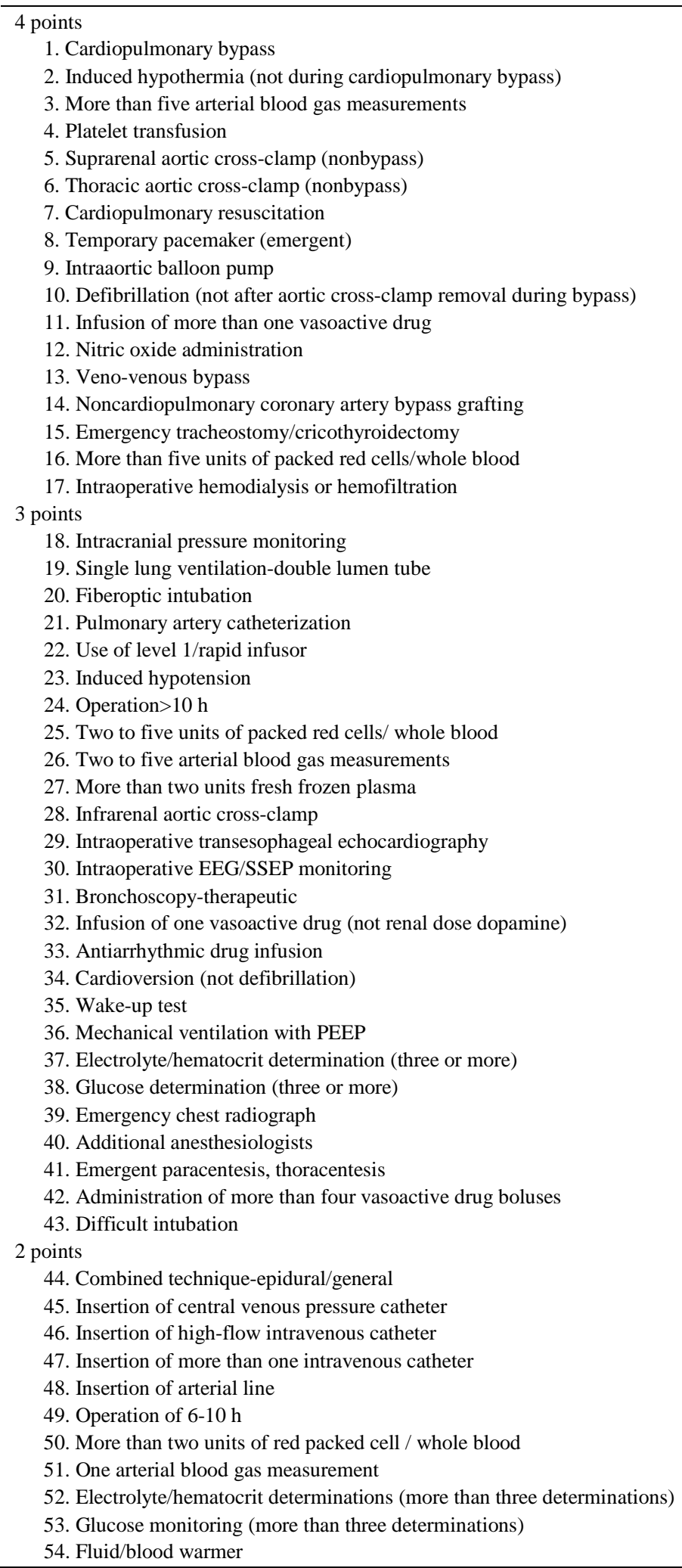




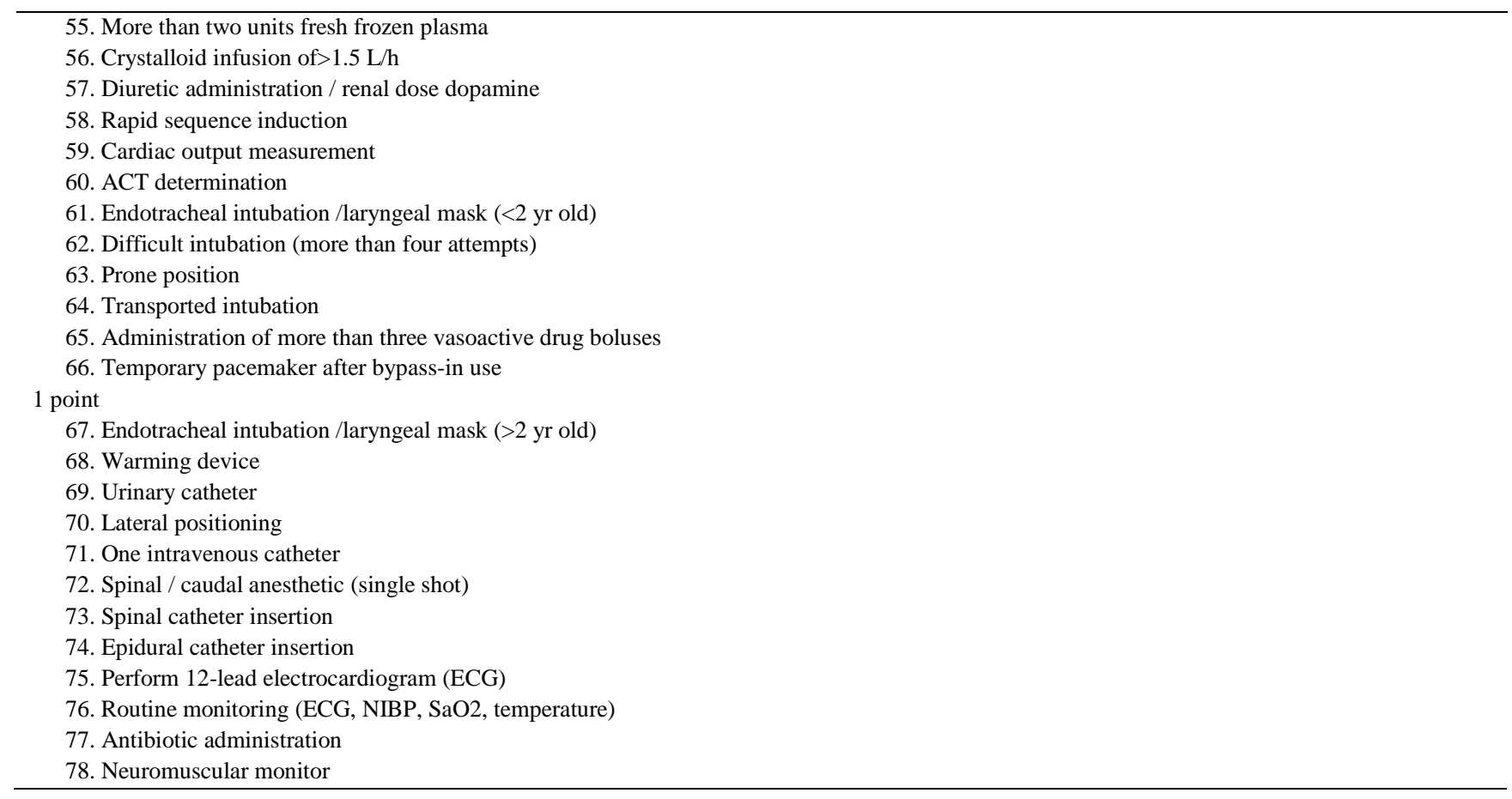

EEG: electroencephalography; SSEP: somatosensory evoked potential; PEEP: positive end-expiratory pressure; ACT: activated coagulation time; NIBP: non-invasive blood pressure; $\mathrm{SaO}_{2}$ : arterial oxygen saturation.

\section{Table 3. Surgical Complexity Classification}

1. Minor: dilatation and curettage, cataract extraction, drainage of rectal abcess, perianal fistul repairment, hemorroidectomy, plenoidal sinus extraction, hidroselectomy, varicoselectomy, adenotonsillectomy, myringotomy tubes, debritmant of a surgical wound, implant extraction (1 point)

2. Moderate: appendectomy, inguinal herniography, cholecystectomy, mastectomy, prostatectomy, transuretral resection of prostate/bladder, penil procedures, tyroidectomy, myomectomy, laminectomy, nephrectomy, open reduction and internal fixation of hip fractures, reconstrictive procedures, strabismus (2 points)

3. Major: laparotomy, bowel resection, cholecystectomy with choledochotomy, major amputations, posterior spine fusion, abdominal hysterectomy, hip/knee replacement, reimplantations, cleft lip-palate deformities (4 points)

4. Major plus: aortic procedures, abdominal-perineal resection, pancreatic or liver resection, esophagogastrectomy, craniotomy, cardiac surgery, anterior-posterior spine instrumentation, all oncologic surgical procedures (8 points)

Adapted from Copeland et al [3] and modified.

Table 4. Patient's data (number -n-, percentage-\%-)

\begin{tabular}{|c|c|c|}
\hline & $\mathrm{n}$ & $\%$ \\
\hline Total number of patients & 859 & \\
\hline Males & 438 & 50.99 \\
\hline Females & 421 & 49.01 \\
\hline \multicolumn{3}{|l|}{ ASA classification } \\
\hline ASA I & 397 & 46.22 \\
\hline ASA II & 300 & 34.92 \\
\hline ASA III & 151 & 17.58 \\
\hline ASA IV & 11 & 1.28 \\
\hline \multicolumn{3}{|l|}{ Type of anesthesia } \\
\hline General & 668 & 77.77 \\
\hline Regional & 191 & 22.23 \\
\hline \multicolumn{3}{|l|}{ Surgical complexity } \\
\hline Minor & 154 & 17.93 \\
\hline Moderate & 421 & 49.01 \\
\hline Major & 172 & 20.02 \\
\hline Major plus & 112 & 13.04 \\
\hline
\end{tabular}

Table 5. ASA status and I-TIS scores for various types of operations

\begin{tabular}{lcccc}
\hline & Age (yr) & ASA & I-TIS & Dur. of anesthesia (min) \\
\hline General surgery & $50.34 \pm 16.08$ & $1.85 \pm 0.73$ & $5.97 \pm 5.65$ & $131.82 \pm 85.96$ \\
Orthopedic surgery & $47.41 \pm 17.89$ & $1.80 \pm 0.87$ & $10.62 \pm 5.63$ & $241.92 \pm 108.44$ \\
Neurosurgery & $45.34 \pm 24.90$ & $1.85 \pm 0.83$ & $7.87 \pm 5.65$ & $180 \pm 142.49$ \\
Otorhinolaryngologic & surgery & $1.5 \pm 0.75$ & $6.92 \pm 7.69$ & $160.46 \pm 167.14$ \\
Urological surgery & $34.79 \pm 21.04$ & $1.61 \pm 0.64$ & $5.61 \pm 4.89$ & $124.21 \pm 104.86$ \\
Gynecological surgery & $41.66 \pm 21.19$ & $2.06 \pm 0.89$ & $7.67 \pm 2.84$ & $91.33 \pm 53.16$ \\
Plastic and Reconstrictive surgery & $49.06 \pm 12.26$ & $1.53 \pm 0.74$ & $4.1 \pm 0.91$ & $140.25 \pm 103.15$ \\
Ocular surgery & $39.9 \pm 12.25$ & $1.59 \pm 0.66$ & $3.07 \pm 2.78$ & $107.30 \pm 67.59$ \\
\hline
\end{tabular}

Values are mean \pm SD. 
Table 6. Distribution of patients according to ASA, surgical complexity classification and I-TIS scores

\begin{tabular}{|c|c|c|c|c|c|}
\hline ASA status & $\mathrm{n}$ & Age, yr (mean \pm SD) & Surgical complexity (mean \pm SD) & I-TIS (mean \pm SD) & (Range) \\
\hline I & 397 & $29.09 \pm 17.01$ & $2.23 \pm 1.23$ & $4.77 \pm 3.28$ & $3-21$ \\
\hline II & 300 & $51.57 \pm 16.15$ & $3.42 \pm 2.37$ & $6.97 \pm 6.35$ & 3-32 \\
\hline III & 151 & $63.32 \pm 14.39$ & $5.0 \pm 2.69$ & $10.16 \pm 6.75$ & 3-33 \\
\hline IV & 11 & $63.4 \pm 11.87$ & $5.8 \pm 1.5$ & $14.2 \pm 8.19$ & 3-35 \\
\hline
\end{tabular}

Table 7. Distribution of the outcome of the patients according to Surgical Complexity Classification

\begin{tabular}{|c|c|c|c|c|}
\hline & $\begin{array}{c}\mathrm{PACU}<1 \mathrm{hr} \\
\underline{\mathrm{n}(\%)}\end{array}$ & $\begin{array}{c}\text { PACU }>1 \mathrm{hr} \\
\underline{\mathrm{n}(\%)}\end{array}$ & $\begin{array}{c}\mathrm{ICU}<24 \mathrm{hr} \\
\underline{\mathrm{n}(\%)} \\
\end{array}$ & $\begin{array}{c}\mathrm{ICU}>24 \mathrm{hr} \\
\mathrm{n}(\%) \\
\end{array}$ \\
\hline Minor(1) & 152(98.7) & $2(1.3)$ & - & - \\
\hline Moderate(2) & 419(99.5) & $2(0.5)$ & - & - \\
\hline Major(4) & $160(93.02)$ & 12(6.98) & - & - \\
\hline Major plus(8) & 93(83.0) & 14(12.5) & $3(2.7)$ & $2(1.8)$ \\
\hline
\end{tabular}

Correlations between the ASA physical status and the I-TIS scores were examined with Spearman correlation coefficients. The correlation between the I-TIS and surgical complexity was determined by using a logarithmic correlation coefficient. Age of the patients, duration of anesthesia and I-TIS scores were expressed as a mean \pm standard deviation.

\section{Results}

After approval of Scientific Research Ethics Committee and patients' informed consent, a total of 859 anesthetic procedures were evaluated. The intervention received a value of 1-4 points, with a maximum possible score of 202. Each patient was given at least 3 points for endotracheal intubation/laryngeal mask insertion, one intravenous catheter and routine monitoring. Patient's data were summarized in Table 4. One-hundred-fifty-four (17.92\%) patients underwent operations classified as surgical complexity score of 1,421 operations (49.01\%) having a score of 2 , 172 (20.02\%) and 112 (13.03\%) operations having a score of 4 and 8 respectively. Distribution of surgical procedures according to age, duration of anesthesia, their ASA status and I-TIS scores were shown in Table 5. The highest scores were with anterior-posterior spinal instrumentation, total laryngectomy and intracranial clipping of an aneurysm. Variations of ASA status according to age, surgical complexity and I-TIS scores were summarized in Table 6.

The association of the I-TIS score with ASA physical status scoring was examined. The correlation coefficient of the ASA with I-TIS was $r=0.55(\mathrm{p}<0.01)$. The correlation between the surgical complexity and the I-TIS was $r=0.66(\mathrm{p}<0.001)$.

Distribution of the patients according to the outcome was shown in Table 7. Five patients with ASA IV and I-TIS score more than 25 were admitted to intensive care unit. Their surgical complexity was a major plus (8 points). Two of them were followed up six hours and the others stayed more than 24 hours. No mortality was recorded.

\section{Discussion}

Perioperative assessment of the patients is a topic which is commonly discussed in anesthesiology society to define the comorbidities and other risk factors affecting the postoperative status of the patients [6]. Preoperative assessments serve medical optimization of the patients preoperatively for decreasing morbidity and improving outcomes. For this reason, the preoperative visit must be patient-directed, targeted interventions rather than protocolized routine preoperative preparations [7]. In 2009, a report from the Centers for Disease Control and Prevention claimed that more than 34 million ambulatory surgical visits were performed in the United States annually, and the reported safety profile of outpatient surgery has historically been excellent [8].

Different approaches have been made to verify the relations between surgical procedures and the possibility of perioperative adverse events. An internet-based program was established for assessment of preoperative cardiac risk and it may help physicians to establish the risk by entering variables on this program [9].

Risk stratification scoring systems can estimate the population risk, such as the American Society of Anesthesiologists Physical Status score (ASA-PS), and they may estimate the individual Risk such as the Lee Revised Cardiac Risk Index (RCRI), Charlson Index and Physiological and Operative Severity Score for the enUmeration of Morbidity and Mortality (POSSUM). Pre-operative Therapeutic Intervention Score is another scoring system using diagnostic and therapeutic interventions as its variables [10].

Scoring systems and risk predictors were designed to classify the severity of illness or the course of diagnosis and therapeutic interventions and to perform a risk stratification [11]. The ASA grading has been the most important instrument for assessing the patients' baseline health status and also applied with other variables to predict postoperative complications but significant variations should be considered in large and culturally heterogeneous countries [12]. It's been previously shown that increase in intraoperative blood loss, duration of postoperative ventilation, duration of intensive care stay, rates of pulmonary and cardiac complications, and in-hospital mortality significantly related in increase the ASA status from I to IV [13].

The development of objectives for the I-TIS was for an easily used scoring system to quantify the extent of physiological monitoring, therapeutic or other (non-surgical) interventions, and biochemical diagnostic testing performed during surgery. Klein et al [4] suggested that the score correlated well with surgical complexity and was able to 
differentiate between the intensity of care during various surgical procedures. As the authors mention that limitation of the evaluation of score which was performed in a single institution. There may be institutional differences in routine monitorization during surgical procedures. In our institution, central venous catheterization and invasive arterial monitorization were applied to all major operations. So, this adds four points to score. We found that there was a correlation between ASA and I-TIS scores and surgical complexity was well correlated with I-TIS. These results are similar to the results of Klein et al's study [4].

It was reported that I-TIS should be evaluated by multi-center approach for the exact definition of its validity for preoperative assessment and prediction the strength of postoperative care. Further, its usefulness is not certain in some situations like trauma and ICU-bound postoperative patients and it was claimed to be simplified for easy use by reducing the number of variables [14].

In order to find out whether a score is appropriate for a specific situation, a number of aspects have to be considered. These aspects include quality characteristics of the measurement instruments, as well as its applicability. Reliability describes the exactness with which a scoring measurement can be performed, how accurate a score can be reproduced [15].

In order to provide accurate and reliable outcome data, precise definitions are essential to ensure standardization and uniformity of data collection. The reliability and validation of a process should be assessed at regular intervals [16]. We studied this score for the assessment of reliability and validity. However, its use is neither simple nor rapid and time-consuming. In contrast, the ASA classification represents a simple estimation of physiological status and can be applied to every patient.

The correlation between ASA classification and postoperative mortality has been previously reported and absolute mortality rates showed considerable variation $[17,18]$. Wolters et al [19] concluded that ASA physical status classification was a predictor of postoperative outcome. Their data, with mortality rates of $0.1 \%$ for ASA I, $0.7 \%$ for ASA II, 3.5\% for ASA III, $18.3 \%$ for ASA IV and $93.3 \%$ for ASA $\mathrm{V}$, were based on all deaths in hospital after surgical intervention. Donati et al [20] developed the logistic regression model for predicting the operative risk. Although they suggested this new model could be helpful for both surgeons and anesthetists, it was complicated and confusing.

The Physiological and Operative Severity Score for the enUmeration of Mortality and morbidity (POSSUM) scoring systems have been validated in patients undergoing general, colorectal and vascular surgery [3,21,22]. This score was devised in the UK and has been used widely, but the application of it has been limited outside the UK. Yii et all [23] confirmed that this system was applicable to the Malaysian setting.

As previously mentioned ASA scoring system may show significant variation in large and culturally heterogeneous countries, but it seems still widely and easily used scoring system. I-TIS scoring system may be validated to our surgical patients but the reliability of this score is debatable. Until a new scoring system is introduced, ASA scoring system will sustain its popularity for perioperative risk adjustment of the surgical patients.

\section{References}

[1] Saklad M. Grading of patients for surgical procedures. Anesthesiology 1941; 2: 281-4.

[2] Dripps RD. New classification of physical status. Anesthesiology 1963; 24: 111.

[3] Copeland GP, Jones D, Walters M. POSSUM: a scoring system for surgical audit. Br J Surg 1991; 78(3): 355-60.

[4] Klein N, Weissman C. Evaluating intraoperative therapeutic and diagnostic interventions. Anesth Analg 2002; 95 (5): 1373-80.

[5] Keene AR, Cullen DJ. Therapeutic intervention scoring system: update 1983. Crit Care Med 1983; 11(1):1-3.

[6] Spiegelhalter DJ, Aylin P, Best NG, Evans SJW, Murray GD. Commissioned analysis of surgical performance by using routine data: lessons from Bristol inquiry. Journal of the Royal Statistical Society: Series A 2002; 165(2): 191-221.

[7] Hofer J, Chung E, Sweitzer BJ. Preanesthesia evaluation for ambulatory surgery: do we make a difference? Curr Opin Anaesthesiol 2013; 26(6):669-76.

[8] Cullen KA, Hall MJ, Golosinskiy A. Ambulatory surgery in the United States, 2006. Natl Health Stat Report 2009; 28(11):1-25.

[9] Cardiac risk assessment. Br Med J. Best Practice. http://bestpractice.bmj.com/best-practice/monograph/954.html. [Accessed 25 February 2018].

[10] Barnett S, Moonesinghe SR. Clinical risk scores to guide perioperative management. Postgrad Med J 2011; 87 (1030): 535-541.

[11] Junger A, Engel J, Quinzio L, Banzhaf A, Jost A, Hempelmann G. Risk predictors, scoring systems and prognostic models in anesthesia and intensive care. Part I: anesthesia. Anasthesiol Intensivmed Notfallmed Schmerzther 2002; 37(9): 520-7.

[12] Ranta S, Hynynen M, Tammisto T. A survey of the ASA physical status classification: significant variation in allocation among Finnish anaesthesiologists. Acta Anaesthesiol Scand 1997; 41(5): 629-32.

[13] Wolters U, Wolf T, Stutzer H, Schröder T. ASA classification and perioperative variables as predictors of postoperative outcome. $\mathrm{Br}$ J Anaesth 1996; 77 (2): 217-22.

[14] Weissman C, Klein N. Pre-operative evaluation using therapeutic intensity scoring. Eur J Anaesthesiol 2011; 28 (1): 20-28.

[15] Neugebauer EAM, Lefering R. Severity scores in surgery: what for and needs them? Langenbeck's Arch Surg 2002; 387 (1): 55-58.

[16] Al-Homoud s, Purkayastha S, Aziz O, Smith JJ, Thompson MD, Darzi AW, Stamatakis JD, Tekkis PP. Evaluating operative risk in colorectal cancer surgery: ASA and POSSUM-based predictive models. Surg Oncol 2004; 13(2-3): 83-92.

[17] Marx GF, Mateo CV, Orkin LR. Computer analysis of postanesthetic death. Anesthesiology 1973; 39: 54-58.

[18] Feigal DW, Blaisdell FW, The estimation of surgical risk. Med Clin North Am 1979; 63:1131-43.

[19] Wolters U, Wolf T, Stützer H, Schröder T. ASA classification and perioperative variables as predictors of postoperative outcome. $\mathrm{Br}$ J Anaesth. 1996 Aug; 77(2): 217-22.

[20] Donati A, Ruzzi M, Adrario E et al. A new and feasible model for predicting operative risk. Br J Anaesth 2004; 93: 393-9.

[21] Sagar PM, Hartley MN, Mancey-Jones B, Sedman PC, May J, Macfie J. Comparative audit of colorectal resection with the POSSUM scoring system. Br J Surg 1994; 81(10): 1217-20.

[22] Midwinter MJ, Tytherleigh M, Ashley S. Estimation of mortality and mortality risk in vascular surgery using POSSUM and the Portsmouth predictor equation. Br J Surg 1999; 86(4): 471-4.

[23] Yii MK, Ng KJ. Risk-adjusted surgical audit with the POSSUM scoring system in a developing country. Physiological and Operative Severity Score for the enUmeration of Mortality and morbidity. Br J Surg 2002; 89: 110-3. 